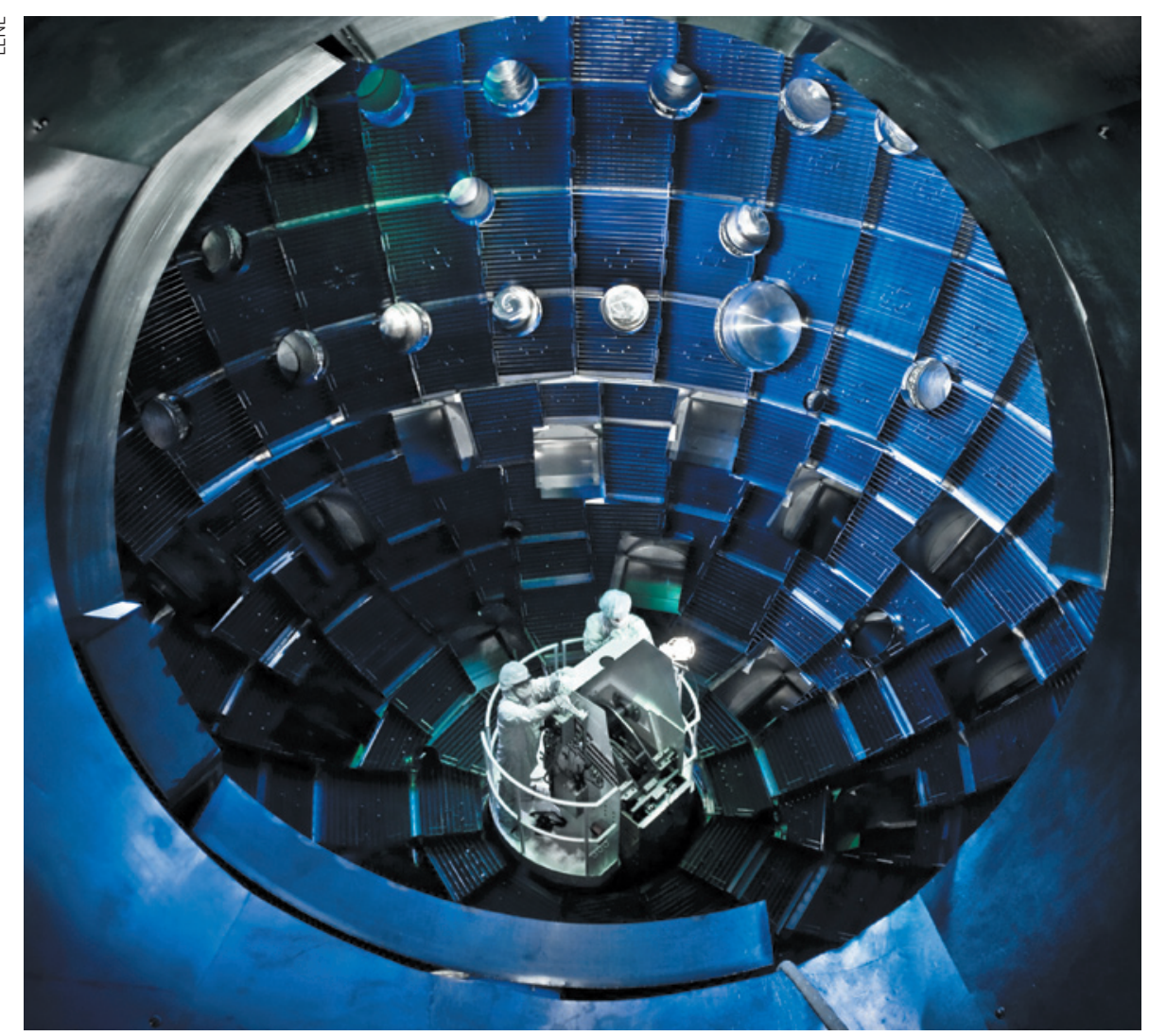

Engineers inspect the fusion chamber at the National Ignition Facility.

ENERGY

\title{
Laser fusion nears crucial milestone
}

\section{National Ignition Facility approaches energy break-even point, but uncertainty over next step persists.}

\section{BY ERIC HAND}

$\mathrm{T}$ This could be the year the National Ignition Facility (NIF) finally lives up to its name. The facility, which boasts the world's largest laser, is designed to trigger fusion by imploding a target pellet of hydrogen isotopes, thereby releasing more energy than will go into the shot. NIF's managers think that the end of their two-year campaign for break-even energy, or 'ignition', is in sight. "We have all the capability to make it happen in fiscal year 2012," says Ed Moses, director of the US\$3.5-billion facility, at the Lawrence Livermore National Laboratory in California.

But even if the champagne corks do get popped, the method - a form of 'inertial confinement' fusion - faces an uncertain future. Would success mean that the US Department of Energy (DOE) will be ready to develop it into an economically viable energy source? And if so, is NIF's laser-based approach the best one? An interim report released on 7 March by a US National Academies panel concludes that it is still too early to tell, and recommends that fusion scientists explore alternative technologies for imploding the fuel.

Glen Wurden, a plasma physicist at Los Alamos National Laboratory in New Mexico, agrees, saying that scientists working on inertial confinement should be wary of putting all their eggs in the laser basket. "It's premature right now," he says. He points to the troubles that have plagued a competing approach to fusion - magnetic confinement - and its flagship project ITER, a \$21-billion international fusion experiment under construction at St-Paul-lez-Durance, France. Wurden blames
ITER's delays and ballooning costs on a premature commitment to a technology known as a tokamak, a doughnut-shaped cage within which powerful electromagnets confine a fusion plasma.

Despite early confidence, bolstered by favourable computer models, NIF too has lagged behind schedule. "It thought it had ignition in the bag," says Wurden. Instead, NIF's approach to heating and compressing the hydrogen isotopes has proved troublesome. In what is known as indirect drive, the laser's multiple beams are focused at the openings in a pencil-eraser-sized gold cylinder called a hohlraum, blasting the insides to create X-rays. The X-rays then heat and squeeze the fuel pellet inside the hohlraum to produce fusion. But unexpectedly turbulent interactions between the laser light and the plasma inside the hohlraum sap energy from the beams. That could wipe out any gains as NIF managers ramp up the laser energy to the threshold needed for ignition.

The NIF team has made steady progress, however. When the push for ignition began 18 months ago, the facility was achieving $1 \%$ of the conditions thought to be needed for ignition. Now the figure stands at $10 \%$, and the pace is quickening: a record 57 shots were taken in January alone (see 'Power play'). The team is also studying an array of tweaks, including encasing the fuel in beryllium or diamond instead of plastic and changing the hohlraum material or its shape. Moses says that it might also be possible to crank up NIF's peak energy from the 1.8 megajoules estimated to be needed for break-even to 2.2 megajoules.

Still, as the National Academies' report notes, other approaches might provide an easier route to ignition and ultimately to a practical power plant. But who will pay for developing them? Most of the research on inertial confinement in the United States and worldwide has been supported by national security and weapons complexes, which want to study fusion for weapons purposes, not for electric power. Today, laser fusion in the United States makes its home within the National Nuclear Security Administration, the branch of the DOE responsible for stewardship of the nuclear stockpile.

Within the DOE's Office of Science, almost no money goes to inertial confinement research. The vast majority supports magnetic confinement fusion, and increasingly, that money is paying for ITER. Stephen Dean, president of Fusion Power Associates, an advocacy group based in Gaithersburg, Maryland, says that even if the academies' panel in its final report calls for a robust inertial confinement energy programme, the research will struggle to find a home with the office of science. "I think it'll just ignore it," he says. "ITER is obviously its top priority, and they're struggling like mad to save it."

The $\$ 460$ million requested for the NIF effort in 2013 will allow it to vary its 


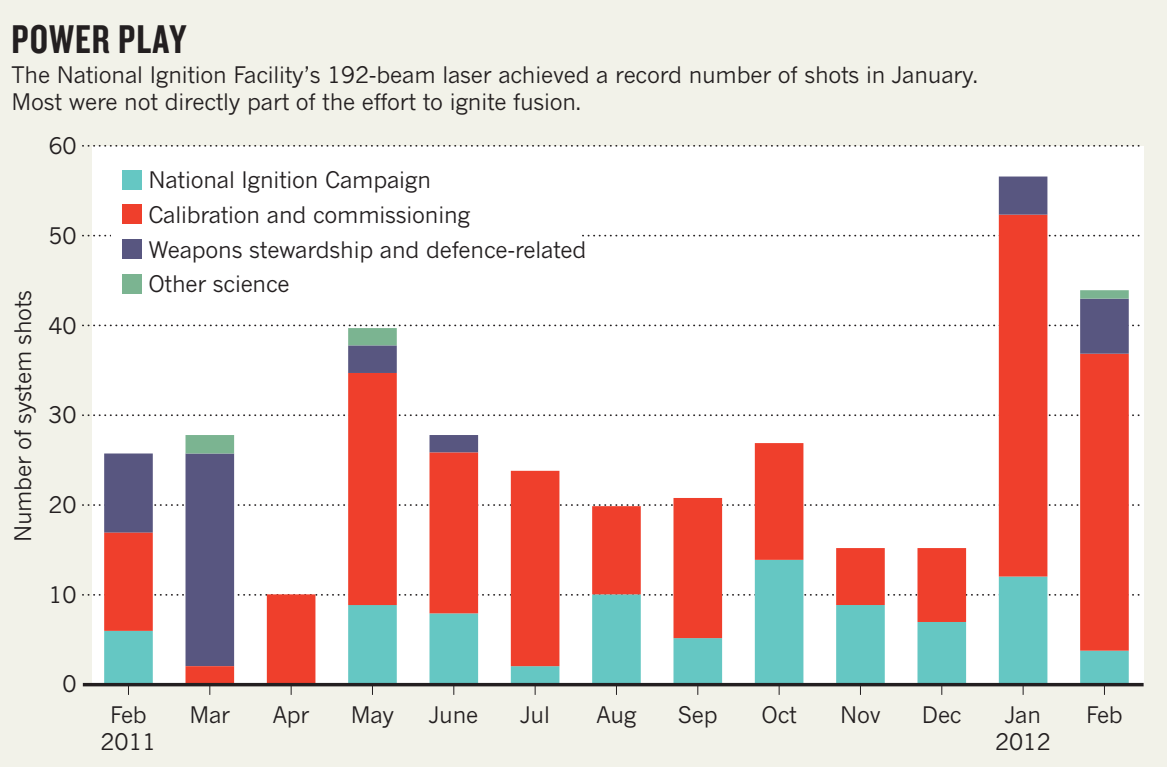

- approach. For example, plasma physicists at the University of Rochester in New York want to adapt NIF's lasers so that they can implode a hydrogen-isotope pellet directly and dispense with the hohlraum.

The NIF scientists aren't waiting for alternative approaches to catch up, however. Even before achieving ignition, they are racing to plan their next project, a demonstration power plant that they call LIFE, for Laser Inertial Fusion Energy. To be economic, the plant would have to produce more than 50 times more energy from each shot than it puts in, and would have to boost repetition rates from a few shots a day to 15 per second - no mean feat.

In the quiet, cavernous NIF facility is a mock-up of one of the modular beam lines that would make up LIFE, small enough to fit in the back of a truck. Whereas NIF's set-up uses thousands of bulky flashbulbs to pump energy into the glass lasers, LIFE would use small, transistor-powered light-emitting diodes. Moses dismisses the notion that it's too early to commit to lasers as the drivers of a future power plant. Because of investment in lasers and transistors for consumer electronics, the world has already chosen, he says. Historians will look back, and "they'll see the transistor and the laser as the turning point".

LIFE director Mike Dunne says that the capital costs for the pilot plant would be about $\$ 4$ billion, and it could be putting hundreds of megawatts into the grid by the early 2020s - at least a decade earlier than the magnetic-fusion community hopes to deliver a practical power plant. Recalling the first time he presented the LIFE concept to magneticfusion researchers at a conference a few years ago, Moses says "The response to it was almost violent: 'This cannot be.' They were shocked at the ambition of it for sure. And they still are." -

\section{Computers can rapidly scan through thousands of research papers to make useful connections, but work is being slowed by publishers' unease.}

\section{BY RICHARD VAN NOORDEN}

$\mathrm{W}$ hen he was a keen young biology graduate student in 2006, Max Haeussler wrote a computer program that would scan, or 'crawl', plain text and pull out any DNA sequences. To test his invention, the naive text-miner downloaded around 20,000 research papers that his institution had paid to access - and promptly found his IP address blocked by the papers' publisher.

It was not until 2009 that Haeussler, then at the University of Manchester, UK, and now at the University of California, Santa Cruz, returned to the project in earnest. He had come to realize that standard site licences do not permit systematic downloads, because publishers fear wholesale theft of their content. So Haeussler began asking for licensing terms to crawl and text-mine articles. His goal was to serve science: his program is a key part of the text2genome project, which aims to use DNA sequences in research papers to link the publications to an online record of the human genome. This could produce an annotated genome map linked to millions of research articles, so that biologists browsing a genomic region could immediately click through to any relevant papers.

But Haeussler and his text2genome colleague Casey Bergman, a genomicist at the University of Manchester, have spent more than two years trying to agree terms with publishers - and often being ignored or rebuffed. "We've learned it's a long, hard road with every journal," says Bergman.

Many publishers say that they will allow their subscribers to text-mine, subject to contract and the text-miners' intentions, and point to a number of successful agreements. But like many early advocates of the technology, Haeussler and Bergman complain that publishers are failing to cope with requests, and so are holding up the progress of research. What is

\section{DNATURE.COM} To read more about go.nature.com/rubywp text-mining, see: more, they point out, as text-mining expands, it will be impractical for individual academic teams to spend years each working out bilateral agreements with every publisher.

With his frustration boiling over, Haeussler last week started a project to e-mail all the main science publishers for permission to mine their content. He will log their responses online (at http://text.soe.ucsc.edu) in the hope of raising awareness of the problem.

Academia is abuzz with excitement over textmining. Thanks to growing computer power, software can recognize, extract and index scientific information from vast amounts of plain text, allowing computers to read and organize a body of knowledge that is expanding too fast for any human to keep up. 'Semantic software' is starting to record the relationships between scientific 'entities' - for example, between a particular drug and a specific enzyme.

For pharmaceutical firms, text-mining is "a basic necessity" that assists drug development, says Raul Rodriguez-Esteban, a computational 